\title{
ON THE BIVARIATE GENERALIZED POISSON DISTRIBUTION
}

\author{
RALUCA VERNIC \\ University "Ovidius" Constanta, Romania
}

\begin{abstract}
This paper deals with the bivariate generalized Poisson distribution. The distribution is fitted to the aggregate amount of claims for a compound class of policies submitted to claims of two kinds whose yearly frequencies are a priori dependent. A comparative study with the bivariate Poisson distribution and with two bivariate mixed Poisson distributions has been carried out, based on data concerning natural events insurance in the USA and third party liability automobile insurance in France.
\end{abstract}

\section{KEYWORDS}

Bivariate generalized Poisson distribution; generalized Poisson distribution; bivariate mixed Poisson distributions.

\section{INTRODUCTION}

Whereas numerous bivariate discrete distributions are used in the statistic field (KoCHERlakota and Kocherlakota, 1992), only a few of them, apart from the bivariate Poisson distribution, have been applied in the insurance field. It is worth noting the studys by PICARD (1976), LEMAIRE (1985) and PARTRAT (1993).

In this paper, we discuss the bivariate generalized Poisson distribution (BGPD) in detail. The distribution is derived from the generalized Poisson distribution (CONSUL, 1989; AMBAGASPITIYA and BALAKRISHNAN, 1994) using the trivariate reduction method. In section 2 we present some properties of the BGPD. The method of moments is used in section 3 for estimation of the parameters. We illustrate the usage of this method through two examples in section 4 .

\section{BIVARIATE GENERALIZED POISSON DISTRIBUTION (BGPD)}

\subsection{Development of the distribution}

We use the trivariate reduction method to construct the distribution (KOCHERLAKOTA and KoCHerlakota, 1992). Let $\mathrm{N}_{1}, \mathrm{~N}_{2}$ and $\mathrm{N}_{3}$ be independent generalized Poisson ASTIN BULLETIN, Vol. 27, No. 1, 1997, pp. 23-31 
random variables (GPD), $\mathrm{N}_{1} \sim G P D\left(\lambda_{1}, \theta_{1}\right), i=1,2,3$. Let $X=N_{1}+N_{3}$ and $Y=N_{2}+N_{3}$. We get the joint probability function (p.f.) of (X, Y) as

$$
P(X=r, Y=s)=\sum_{k=0}^{\min (r, s)} f_{1}(r-k) f_{2}(s-k) f_{3}(k),
$$

where $f_{1}(n)$ is the p.f. of the random variable $N_{1}$.

Since $\mathrm{N} \sim \operatorname{GPD}(\lambda, \theta)$, if its p.f. is given by (CONSUL and SHOUKRI, 1985)

$$
f(n)=P(N=n)=\left\{\begin{array}{c}
\frac{\lambda(\lambda+n \theta)^{n-1} \exp (-\lambda-n \theta)}{n !} \text { for } n=0,1,2, \ldots \\
0 \quad, \text { otherwise }
\end{array}\right\} \text {, }
$$

where $\lambda>0, \max (-1,-\lambda / m) \leq \theta<1$ and $m \geq 4$ is the largest positive integer for which $\lambda+\theta m>0$ when $\theta<0$, from (2.1) we have

$$
\begin{aligned}
& P(X=r, Y=s)=p(r, s)=\lambda_{1} \lambda_{2} \lambda_{3} \exp \left\{-\left(\lambda_{1}+\lambda_{2}+\lambda_{3}\right)-r \theta_{1}-s \theta_{2}\right\} \\
& \sum_{k=0}^{\min (r, s)} \frac{1}{(r-k) !(s-k) ! k !} \cdot\left(\lambda_{1}+(r-k) \theta_{1}\right)^{r-k-1}\left(\lambda_{2}+(s-k) \theta_{2}\right)^{r-k-1}\left(\lambda_{3}+k \theta_{3}\right)^{k-1} \\
& \exp \left\{k\left(\theta_{1}+\theta_{2}-\theta_{3}\right)\right\}, \mathrm{r}, \mathrm{s} \in N .
\end{aligned}
$$

\subsection{Properties of the distribution}

Remark All the formulas that follows for the GPD are taken from AMBAGASPITIYA and BALAKRISHNAN (1994) and the general equations for a bidimensional distribution are from KOCHERLAKOTA and KOCHERLAKOTA (1992).

\section{Probability generating function (pgf)}

The pgf of a random variable $\mathrm{N}$ is defined by $\prod_{N}(t)=E\left(t^{N}\right)$ and the pgf of the pair of random variables $(\mathrm{X}, \mathrm{Y})$ is $\prod\left(t_{1}, t_{2}\right)=E\left(t_{1}^{X} t_{2}^{Y}\right)$.

Let the pgf's of the random variables under consideration be $\prod_{t}(t), \mathrm{i}=1,2,3$. Then the joint pgf of $(X, Y)$ is

$$
\prod\left(t_{1}, t_{2}\right)=\prod_{1}\left(t_{1}\right) \prod_{2}\left(t_{2}\right) \prod_{3}\left(t_{1} t_{2}\right)
$$

For simplicity, we assume the parameters $\theta_{t}>0, i=1,2,3$. AMBAGASPITIYA and BALAKRISHNAN (1994) has expressed the pgf of the GPD in terms of Lambert's W function when $\theta>0$, as follows:

$$
\prod_{N}(t)=\exp \left\{-\frac{\lambda}{\theta}[W(-\theta z \exp (-\theta))+\theta]\right\}
$$


where the Lambert's $W$ function is defined as $W(x) \exp (W(x))=x$. For more details about this function see CORLESS et al. (1994).

From (2.4) and (2.5), the pgf of $(\mathrm{X}, \mathrm{Y})$ is

$$
\begin{aligned}
\prod\left(t_{1}, t_{2}\right)= & \exp \left\{-\frac{\lambda_{1}}{\theta_{1}} W\left(-\theta_{1} t_{1} \exp \left(-\theta_{1}\right)\right)-\frac{\lambda_{2}}{\theta_{2}} W\left(-\theta_{2} t_{2} \exp \left(-\theta_{2}\right)\right)-\right. \\
& \left.-\frac{\lambda_{3}}{\theta_{3}} W\left(-\theta_{3} t_{1} t_{2} \exp \left(-\theta_{3}\right)\right)-\lambda\right\},
\end{aligned}
$$

with $\lambda=\lambda_{1}+\lambda_{2}+\lambda_{3}$.

\section{Moment generating function (mgf)}

If the mgf of $\mathrm{N}_{1}$ is $M_{1}(t), i=1,2,3$ then the $\operatorname{mgf}$ of $(\mathrm{X}, \mathrm{Y})$ is

$$
M\left(t_{1}, t_{2}\right)=M_{1}\left(t_{1}\right) M_{2}\left(t_{2}\right) M_{3}\left(t_{1}+t_{2}\right) \text {. }
$$

The mgf of the GPD, when $\theta>0$, is given by

$$
M_{N}(t)=\exp \left\{-\frac{\lambda}{\theta}[W(-\theta \exp (-\theta+t))+\theta]\right\} .
$$

Using (2.8) in (2.7) we get

$$
\begin{aligned}
M\left(t_{1}, t_{2}\right)= & \exp \left\{-\frac{\lambda_{1}}{\theta_{1}} W\left(-\theta_{1} \exp \left(-\theta_{1}+t_{1}\right)\right)-\frac{\lambda_{2}}{\theta_{2}} W\left(-\theta_{2} \exp \left(-\theta_{2}+t_{2}\right)\right)-\right. \\
& \left.-\frac{\lambda_{3}}{\theta_{3}} W\left(-\theta_{3} \exp \left(-\theta_{3}+t_{1}+t_{2}\right)\right)-\lambda\right\}
\end{aligned}
$$

\section{Moments}

The expressions for the first four central moments of the GPD are as follows:

$$
\begin{aligned}
& E(N)=\mu_{1}=\lambda M \\
& V(N)=\mu_{2}=\lambda M^{3} \\
& \mu_{3}=\lambda(3 M-2) M^{4} \\
& \mu_{4}=3 \lambda^{2} M^{6}+\lambda\left(15 M^{2}-20 M+6\right) M^{5}, \quad \text { where } M=(1-\theta)^{-1} .
\end{aligned}
$$

Since $X=N_{1}+N_{3}$ and $N_{1}, N_{3}$ independent, we have $E(X)=E\left(N_{1}\right)+E\left(N_{3}\right)$ and $V(X)=V\left(N_{1}\right)+V\left(N_{3}\right)$, so that

$$
\left\{\begin{array}{l}
E(X)=\lambda_{1} M_{1}+\lambda_{3} M_{3} \\
V(X)=\lambda_{1} M_{1}^{3}+\lambda_{3} M_{3}^{3} \\
E(Y)=\lambda_{2} M_{2}+\lambda_{3} M_{3} \\
V(Y)=\lambda_{2} M_{2}^{3}+\lambda_{3} M_{3}^{3}
\end{array}\right\} .
$$


Let $\mu_{r, s}=E\left[\left(X-\mu_{X}\right)^{r}\left(Y-\mu_{Y}\right)^{s}\right]$ be the $(\mathrm{r}, \mathrm{s})^{\mathrm{th}}$ central moment of $(\mathrm{X}, \mathrm{Y})$. The equation for $\mu_{\mathrm{r} s}$ given $\mu_{k}^{(l)}$ the $\mathrm{k}^{\text {th }}$ central moment of $N_{1}, i=1,2,3$, is

$$
\mu_{r, s}=\sum_{i=0}^{r} \sum_{J=0}^{s}\left(\begin{array}{l}
r \\
i
\end{array}\right)\left(\begin{array}{l}
s \\
j
\end{array}\right) \mu_{i}^{(1)} \mu_{J}^{(2)} \mu_{r+s-i-\jmath}^{(3)} .
$$

Hence

$$
\left\{\begin{array}{l}
\mu_{11}=\lambda_{3} M_{3}^{3} \\
\mu_{21}=\mu_{12}=\lambda_{3}\left(3 M_{3}-2\right) M_{3}^{4}
\end{array}\right\}
$$

This is enough to apply the method of moments.

\section{Recurrence relations}

The terms in the first row and column can be computed using the univariate generallzed Poisson distribution, as is seen from

$$
\begin{array}{ll}
p(0,0)=\exp \{-\lambda\} & \\
p(0, s)=\frac{\lambda_{2}\left(\lambda_{2}+s \theta_{2}\right)^{s-1}}{s !} \exp \left\{-\lambda-s \theta_{2}\right\}=f\left(s ; \lambda_{2}, \theta_{2}\right) \exp \left\{-\left(\lambda_{1}+\lambda_{3}\right)\right\}, \quad s>0 \\
p(r, 0)=\frac{\lambda_{1}\left(\lambda_{1}+r \theta_{1}\right)^{r-1}}{r !} \exp \left\{-\lambda-r \theta_{1}\right\}=f\left(r ; \lambda_{1}, \theta_{1}\right) \exp \left\{-\left(\lambda_{2}+\lambda_{3}\right)\right\}, \quad r>0 .
\end{array}
$$

Given the probabilities in the first row and column, the probabilities for $r \geq 1, s \geq 1$ can be computed recursively as

$$
p(r, s)=\lambda_{3} \exp \{\lambda\} \sum_{k=0}^{\min \{r, s\}} \frac{1}{k !} p(r-k, 0) p(0, s-k)\left(\lambda_{3}+k \theta_{3}\right)^{k-1} \exp \left\{-k \theta_{3}\right\} .
$$

\section{Independence}

Using (2.12) we have $\operatorname{cov}(X, Y)=\lambda_{3} M_{3}^{3}$, hence

$$
\rho_{X, Y}=\frac{\lambda_{3} M_{3}^{3}}{\left[\left(\lambda_{1} M_{1}^{3}+\lambda_{3} M_{3}^{3}\right)\left(\lambda_{2} M_{2}^{3}+\lambda_{3} M_{3}^{3}\right)\right]^{1 / 2}}
$$

Since $\lambda_{3} \geq 0$ and $M_{3}>0$, it follows that for this model $\rho_{X v} \geq 0$. This shows that the condition of zero correlation is a necessary and sufficient condition for the independence of the random variables $\mathrm{X}$ and $\mathrm{Y}$. 


\section{Marginal distributions}

The marginal distributions are:

$$
\begin{aligned}
& P(X=r)=\lambda_{1} \lambda_{3} \exp \left\{-\left(\lambda_{1}+\lambda_{3}\right)-r \theta_{3}\right\} \sum_{i=0}^{r} \frac{\left(\lambda_{1}+i \theta_{1}\right)^{i-1}\left(\lambda_{3}+(r-i) \theta_{3}\right)^{r-l-1}}{i !(r-i) !} . \\
& \exp \left\{-i\left(\theta_{1}-\theta_{3}\right)\right\} \\
& P(Y=s)=\lambda_{2} \lambda_{3} \exp \left\{-\left(\lambda_{2}+\lambda_{3}\right)-s \theta_{3}\right\} \sum_{i=0}^{s} \frac{\left(\lambda_{2}+i \theta_{2}\right)^{i-1}\left(\lambda_{3}+(s-i) \theta_{3}\right)^{s-i-1}}{i !(s-i) !} . \\
& \exp \left\{-i\left(\theta_{2}-\theta_{3}\right)\right\} .
\end{aligned}
$$

In particular, if $\theta_{1}=\theta_{2}=\theta_{3}=\theta$, this reduces to $X \sim G P\left(\lambda_{1}+\lambda_{3}, \theta\right)$ and $Y \sim$ $G P\left(\lambda_{2}+\lambda_{3}, \theta\right)$.

\section{ESTIMATION OF THE PARAMETERS: METHOD OF MOMENTS}

Let $\left(x_{n}, y_{t}\right), i=1,2, \ldots, n$ be a random sample of size $n$ from the population. We will assume that the frequency of the pair $(r, s)$ is $n_{r s}$ for $r=0,1,2, \ldots, s=0,1,2, \ldots$ We recall that $\sum_{r, s} n_{r s}=n$. Also

$$
\left\{\begin{array}{l}
\bar{x}=\frac{1}{n} \sum_{i=1}^{n} x_{i}=\frac{1}{n} \sum_{r=0} r \cdot n_{r+} ; \quad \hat{\sigma}_{X}^{2}=\frac{1}{n} \sum_{r=0}(r-\bar{x})^{2} n_{r+} \\
\bar{y}=\frac{1}{n} \sum_{i=1}^{n} y_{i}=\frac{1}{n} \sum_{s=0} s \cdot n_{+s} ; \hat{\sigma}_{Y}^{2}=\frac{1}{n} \sum_{s=0}(s-\bar{y})^{2} n_{+s} \\
\hat{\mu}_{11}=\frac{1}{n} \sum_{i=1}^{n}\left(x_{t}-\bar{x}\right)\left(y_{t}-\bar{y}\right)=\frac{1}{n} \sum_{r, s=0} r \cdot s \cdot n_{r s}-\bar{x} \cdot \bar{y} \\
\hat{\mu}_{21}=\frac{1}{n} \sum_{i=1}^{n}\left(x_{i}-\bar{x}\right)^{2}\left(y_{t}-\bar{y}\right)=\frac{1}{n} \sum_{r, s=0}(r-\bar{x})^{2}(s-\bar{y}) n_{r s}
\end{array}\right\}
$$

The classical method of moments consists of equating the sample moments to their populations equivalents, expressed in terms of the parameters. The number of moments required is six, equal to the number of parameters. Using (3.1), (2.11) and (2.12) we have 


$$
\left\{\begin{array}{l}
\bar{x}=\lambda_{1} M_{1}+\lambda_{3} M_{3} \\
\bar{y}=\lambda_{2} M_{2}+\lambda_{3} M_{3} \\
\hat{\sigma}_{X}^{2}=\lambda_{1} M_{1}^{3}+\lambda_{3} M_{3}^{3} \\
\hat{\sigma}_{Y}^{2}=\lambda_{2} M_{2}^{3}+\lambda_{3} M_{3}^{3} \\
\hat{\mu}_{11}=\lambda_{3} M_{3}^{3} \\
\hat{\mu}_{21}=\lambda_{3}\left(3 M_{3}-2\right) M_{3}^{4}
\end{array}\right\} \Leftrightarrow\left\{\begin{array}{l}
M_{3}=\frac{1+\sqrt{1+3 a}}{3} \\
\lambda_{3}=\frac{\hat{\mu}_{11}}{M_{3}^{3}} \\
M_{1}=\sqrt{\frac{\hat{\sigma}_{X}^{2}-\hat{\mu}_{11}}{\bar{x}-\lambda_{3} M_{3}}} \\
\lambda_{1}=\frac{\bar{x}-\lambda_{3} M_{3}}{M_{1}} \\
M_{2}=\frac{\sqrt{\frac{\hat{\sigma}_{Y}^{2}-\hat{\mu}_{11}}{\bar{y}-\lambda_{3} M_{3}}}}{\lambda_{2}=\frac{\bar{y}-\lambda_{3} M_{3}}{M_{2}}}
\end{array}\right\},
$$

where $a=\frac{\hat{\mu}_{21}}{\hat{\mu}_{11}}$.

We use the fact that $\theta<1$, so $M=\frac{1}{1-\theta}>0$, when chosen the solution for $M_{i}$, $i=1,2,3$.

\section{NUMERICAL EXAMPLES}

Example 1: The North atlantic coastal states in the USA (from Texas to Maine) can be affected by tropical cyclones. We divided these states into three geographical zones:

Zone 1: Texas, Louisiane, The Mississipi, Alabama;

Zone 2: Florida;

Zone 3: Other states.

We were interested in studying the joint distribution of the pair $(X, Y)$, where $X$ and $Y$ are the yearly frequency of hurricanes affecting respectively zone 1 and zone 3 . To do that we used the data in table 1, first row in each cell, giving the realizations of (X, Y) observed during the 93 years from 1899 to 1991 (PARTRAT, 1993).

For these data we compute

$$
\begin{array}{lll}
\bar{x}=0.74194, & \hat{\sigma}_{X}^{2}=0.62158, & \hat{\mu}_{11}=0.02532, \\
\bar{y}=0.47312, & \hat{\sigma}_{Y}^{2}=0.52885, & \hat{\mu}_{21}=0.128341 .
\end{array}
$$

Under the hypothesis $(\mathrm{X}, \mathrm{Y})$ bivariate Poisson distributed $P_{2}\left(\lambda_{1}, \lambda_{2}, \mu\right)$, we have from PARTRAT (1993), method of maximum likelihood, the m.l.e. $\hat{\lambda}_{1}=0.71876$, 
$\hat{\lambda}_{2}=0.44994, \hat{\mu}=0.02317$. The theoretical frequencies for $P_{2}\left(\hat{\lambda}_{1}, \hat{\lambda}_{2}, \hat{\mu}\right)$ are given in table 1 , middle row in each cell.

\section{TABLE 1}

COMPARISON OF OBSERVED AND THEORETICAL YEARLY FREQUENCIES OF HURRICANES (1899-1991) HAVING AFFECTED ZONE 1 AND ZONE 3

\begin{tabular}{|c|c|c|c|c|c|}
\hline $\begin{array}{l}\text { Zone } 3 \\
\text { Zone } 1\end{array}$ & 0 & 1 & 2 & 3 & $\Sigma$ \\
\hline 0 & $\begin{array}{l}27 \\
2824 \\
2629\end{array}$ & $\begin{array}{l}9 \\
1271 \\
1126\end{array}$ & $\begin{array}{l}3 \\
286 \\
284\end{array}$ & $\begin{array}{l}2 \\
048 \\
065\end{array}$ & $\begin{array}{l}41 \\
4429 \\
4104\end{array}$ \\
\hline 1 & $\begin{array}{l}24 \\
2030 \\
2381\end{array}$ & $\begin{array}{l}13 \\
979 \\
1029\end{array}$ & $\begin{array}{l}1 \\
235 \\
262\end{array}$ & $\begin{array}{l}0 \\
042 \\
061\end{array}$ & $\begin{array}{l}38 \\
3286 \\
3733\end{array}$ \\
\hline 2 & $\begin{array}{l}8 \\
729 \\
790\end{array}$ & $\begin{array}{l}2 \\
375 \\
347\end{array}$ & $\begin{array}{l}1 \\
096 \\
092\end{array}$ & $\begin{array}{l}0 \\
019 \\
020\end{array}$ & $\begin{array}{l}11 \\
1219 \\
1249\end{array}$ \\
\hline 3 & $\begin{array}{l}1 \\
212 \\
124\end{array}$ & $\begin{array}{l}0 \\
116 \\
056\end{array}$ & $\begin{array}{l}2 \\
032 \\
028\end{array}$ & $\begin{array}{l}0 \\
006 \\
006\end{array}$ & $\begin{array}{ll}3 \\
3 & 66 \\
2 & 14\end{array}$ \\
\hline$\Sigma$ & $\begin{array}{l}60 \\
5795 \\
5924\end{array}$ & $\begin{array}{l}24 \\
2741 \\
2558\end{array}$ & $\begin{array}{l}7 \\
649 \\
666\end{array}$ & $\begin{array}{l}2 \\
115 \\
152\end{array}$ & 93 \\
\hline
\end{tabular}

first row : observed frequency

middle row : theoretical frequency for $P_{2}$ last row : theoretical frequency for BGPD.

The $\chi^{2}$ goodness-of-fit test, after grouping in 7 categories: $(0,0),(0,1),(0,2$ and above), $(1,0),(1,1),(2,0)$, (other cases) to fulfill the Cochran criterium, lead us to $\chi_{o b s}^{2}=\sum(o b s-t h)^{2} / t h=5.96$ and a significance value $\hat{\alpha}$ verifyıng $0.20 \leq \hat{\alpha} \leq$ 054.

We consider now the case of $(\mathrm{X}, \mathrm{Y}) \mathrm{BGPD}$-distributed. Then from the method of moments we have

$$
\left\{\begin{array}{ll}
\lambda_{1}=0.81257, & \theta_{1}=-0.10868 \\
\lambda_{2}=0.44555, & \theta_{2}=0.03995 \\
\lambda_{3}=0.00538, & \theta_{3}=0.40306
\end{array}\right\}
$$

The theoretical frequencies in this case are given in table 1, last row in each cell, and $\chi_{\text {obs }}^{2}=2.66$ for the same categories; $0 \leq \hat{\alpha} \leq 0.85$. 
Example 2: Automobile third party liability insurance.

The claims experience of a large automobile portfolio in France including 181038 liability policies was observed during the year 1989. The corresponding yearly claim frequencies, collected in table 2 (first row in each cell), have been divided into material damage only (type 1 ) and bodily injury (type 2 ) claims. We obtain

$$
\begin{array}{lll}
\bar{x}=0.05100, & \hat{\sigma}_{X}^{2}=0.05388, & \hat{\mu}_{11}=0.00019, \\
\bar{y}=0.00553, & \hat{\sigma}_{Y}^{2}=0.00552, & \hat{\mu}_{21}=0.00023 .
\end{array}
$$

TABLE 2

\begin{tabular}{|c|c|c|c|c|}
\hline $\begin{array}{l}\text { Type } 2 \\
\text { Type } 1\end{array}$ & 0 & 1 & 2 and above & $\Sigma$ \\
\hline 0 & $\begin{array}{l}171345 \\
1713487 \\
1713487 \\
17135130\end{array}$ & $\begin{array}{l}918 \\
8971 \\
8975 \\
92308\end{array}$ & $\begin{array}{l}2 \\
47 \\
46 \\
002\end{array}$ & $\begin{array}{l}17226500 \\
17225050 \\
17225080 \\
17227440\end{array}$ \\
\hline 1 & $\begin{array}{l}8273 \\
82755 \\
82795 \\
824839\end{array}$ & $\begin{array}{l}73 \\
863 \\
849 \\
7101\end{array}$ & $\begin{array}{l}0 \\
07 \\
08 \\
014\end{array}$ & $\begin{array}{l}834600 \\
836250 \\
836520 \\
831954\end{array}$ \\
\hline 2 & $\begin{array}{l}389 \\
3982 \\
3915 \\
41541\end{array}$ & $\begin{array}{l}5 \\
62 \\
70 \\
352\end{array}$ & 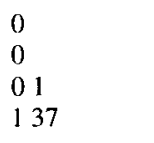 & $\begin{array}{l}39400 \\
40440 \\
39860 \\
42030\end{array}$ \\
\hline 3 & $\begin{array}{l}31 \\
191 \\
213 \\
2218\end{array}$ & $\begin{array}{l}1 \\
04 \\
06 \\
019\end{array}$ & $\begin{array}{l}0 \\
0 \\
0 \\
006\end{array}$ & $\begin{array}{l}3200 \\
1950 \\
2190 \\
2243\end{array}$ \\
\hline $\begin{array}{c}4 \\
\text { and above }\end{array}$ & $\begin{array}{l}1 \\
10 \\
14 \\
132\end{array}$ & 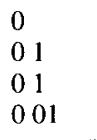 & $\begin{array}{l}0 \\
0 \\
0 \\
0\end{array}$ & $\begin{array}{l}100 \\
110 \\
150 \\
133\end{array}$ \\
\hline$\Sigma$ & $\begin{array}{l}180039 \\
1800425 \\
1800424 \\
18003860\end{array}$ & $\begin{array}{l}997 \\
9901 \\
9901 \\
99781\end{array}$ & $\begin{array}{l}2 \\
54 \\
55 \\
159\end{array}$ & 18103800 \\
\hline
\end{tabular}

COMPARISON OF OBSERVED AND THEORETICAL YEARLY FREQUENCIES

first row : observed frequency

second row : theoretical frequency for $P \_G_{2}$

third row : theoretical frequency for $P-I G_{2}$

last row : theoretical frequency for BGPD. 
For the comparative study we have, from PARTRAT (1993):

- Bivariate Poisson Gamma $P \_G_{2}(a ; r, \beta)$ : the m.l.e. $\left\{\begin{array}{l}\hat{a}=0.10840 \\ \hat{r}=1.00772 \\ \hat{\beta}=19.75693\end{array}\right\}$.

The theoretical frequencies are provided in table 2 , second row in each cell.

- Bivariate Poisson Inverse Gaussian $P-I G_{2}(a ; \mu, \gamma)$ : the m.l.e. $\left\{\begin{array}{l}\hat{a}=0.10840 \\ \hat{\mu}=0.05101 \\ \hat{\gamma}=0.05155\end{array}\right\}$.

The theoretical frequencies are provided in table 2 , third row.

Under the hypothesis (X, Y) BGPD, we have, using (3.1)

$\left\{\begin{array}{ll}\hat{\lambda}_{1}=0.04945, & \hat{\theta}_{1}=0.02701 \\ \hat{\lambda}_{2}=0.00537, & \hat{\theta}_{2}=-0.00266 \\ \hat{\lambda}_{3}=0.00016, & \hat{\theta}_{3}=0.04976\end{array}\right\}$, the theoretical frequencies are given in table 2, last row.

The $\chi^{2}$ goodness-of-fit test is applied on the 9 following categories: $(0,0) ;(0,1)$; $(0,2$ and above); $(1,0) ;(1,1$ and above); $(2,0) ;(3,0) ;(4$ and above, 0$)$; (other cases). For this grouping we obtain:

- In the $P-G_{2}$ case: $\chi_{\text {obs }}^{2}=11.94$ and a significance value $0.03 \leq \hat{\alpha} \leq 0.15$;

- In the $P-I G_{2}$ case: $\chi_{o b s}^{2}=8.8$ and a significance value $0.12 \leq \hat{\alpha} \leq 0.36$.

In the BGPD case we used 7 categories: $(0,0) ;(0,1) ;(1,0) ;(1,1) ;(2,0) ;(3,0)$; (other cases), and we have $\chi_{\text {obs }}^{2}=6.36$ with a significance value $0.00 \leq \hat{\alpha} \leq 0.4$.

\section{REFERENCES}

Ambagaspitiya, R. S. \& Balakrishnan, N. (1994). On the compound generalized Poisson distributions. ASTIN Bulletin 24, 255-263.

Consul, P. C. (1989). Generalized Poisson Distributions: Properties and Applications. Marcel Dekker Inc., New York/Basel.

Consul, P. C. \& Shoukri, M. M. (1985). The generalized Poisson distribution when the sample mean is larger than the sample variance. Communications in Statistics-Simulation and Computation 14, 15331547.

Corless, R. M., Gonnet, G. H., HaRe, D.E.G. \& JefFrey, D. J. (1994). The Lambert W function. To appear in Advances in Computational Mathematics.

KOCHERlakota, S. \& KoCherlakota, K. (1992). Bivariate discrete distributions, Marcel Dekker Inc.

LEMAIRE, J. (1985). Automobile insurance: Actuarial models, Kluwer Publ. 
PARTRAT, C (1993) Compound model for two dependent kinds of claim, XXIVe ASTIN Colloquium, Cambridge

PICARD, P (1976) Generalisation de l'étude sur la survenance des sinistres en assurance automobile, Bulletin de l'Institut des Actuaires Français, Vol. 297, 204-267

\section{Raluca Vernic}

Department of Mathematics and Informatics

University "Ovidius" of Constanta

Bd. Mamaia 124

8700 Constanta

Romania 